\title{
Molecular phylogenetics reveals Messinian, Pliocene, and Pleistocene colonizations of islands by North African shrews
}

\author{
Sylvain Dubey ${ }^{\mathrm{a}, \mathrm{b}, *}$, Kazuhiro Koyasu ${ }^{\mathrm{a}, \mathrm{c}}$, Roumen Parapanov ${ }^{\mathrm{a}}$, Mohammed Ribi ${ }^{\mathrm{c}, \mathrm{d}}$, \\ Rainer Hutterer ${ }^{\mathrm{e}}$, Peter Vogel $^{\mathrm{a}}$ \\ a Department of Ecology and Evolution, University of Lausanne, CH-1015 Lausanne, Switzerland \\ ${ }^{\mathrm{b}}$ Shine Laboratory, School of Biological Sciences, University of Sydney, Hyedon-Laurence Building A08, Sydney, NSW 2006, Australia \\ ${ }^{\mathrm{c}}$ School of Dentistry, Aichi-Gaukin University, Nagoya 464-8650, Japan \\ ${ }^{\mathrm{d}}$ Haut Commissariat aux Eaux et Forêts, Agdal-Rabat, Morocco \\ ${ }^{\mathrm{e}}$ Zoologisches Forschungsmuseum Alexander Koenig, Adenaueralle 160, D-53113 Bonn, Germany
}

Received 5 September 2007; revised 13 December 2007; accepted 14 December 2007

Available online 25 December 2007

\section{Introduction}

Since the seminal work of McArthur and Wilson (1967) on the equilibrium theory of island faunas, colonization and extinction events have remained a focus of research; however, these dynamic events are clearly related to continental islands where the colonization probability and species turnover rates are high (Diamond, 1969). On oceanic islands, and even shelf islands, natural colonization events by terrestrial mammals are so exceptional that local evolution and speciation is more rapid than the arrival of new species (Williamson, 1981). This was the case until at least the end of the last Ice Age, before the arrival of humans. This model is also true for most islands in the Mediterranean basin, as well as the Canary Islands (Juan et al., 2000), situated within the Atlantic Ocean approximately $100 \mathrm{~km}$ off the coast of Morocco. Introductions occurred either during periods of low sea level that led to the formation of filter bridges that allowed the passage of certain organisms, or by sweepstake routs that enabled a small number of organisms to cross by rafting (Simpson, 1940). Such jump dispersals, followed by bottlenecks, genetic drift, and new selective conditions, led to pronounced morphological changes exemplified by dwarf elephants, dwarf hippos, and giant rodents (Sondaar, 1977). All of these mammals became extinct during periods of climatic change or following the immigration of newcomers, but the apoc-

\footnotetext{
* Corresponding author. Address: Shine Laboratory, School of Biological Sciences, University of Sydney, Hyedon-Laurence Building A08, Sydney, NSW 2006, Australia. Fax: +61 293515609.

E-mail address: sylvain.dubey@bio.usyd.edu.au (S. Dubey).
}

alyptic end of most island endemics began with the arrival of humans during the early Holocene (Diamond, 1992). According to Sondaar (1977), the famous dwarfing and gigantism on these islands are in part explained by a predator-free environment.

To our knowledge, in regard to mammals, only four Pleistocene island endemic taxa survived the extinction events in the Mediterranean basin: the Cypriot mouse Mus cypriacus (Cucchi et al., 2006), the "Cyprian shrew" Crocidura suaveolens cypriacus (Dubey et al., 2007a), the Cretan shrew C. zimmermanni (Vogel et al., 1986), and possibly the Sicilian shrew C. sicula on the Siculo-Maltese archipelago (Vogel et al., 1990). Interestingly, these small mammals have no morphological peculiarities and were therefore regarded as continental forms introduced by humans. The endemic character of the mammals from Cyprus was discovered only very recently thanks to molecular analyses and dating of the split from continental forms by molecular clock analyses (Cucchi et al., 2006; Dubey et al., 2007a). The Cretan shrew was discovered thanks to the derived karyotype of $2 n=34$, not found outside of this island (Vogel, 1986).

In the present study, we focus on the Sicilian shrew $C$. sicula and its relatives on other islands as well as continental Africa. These taxa have a complex history that exemplifies the problem of species assignment on islands. In the 1980s, Kotsakis (1984) discovered a fossil shrew, Crocidura esuae, in the Spinagallo cave in Sicily that was considered to be identical to the fossil shrew found in Malta's Ghar Dalam cave, in both cases associated with dwarf elephants. At that time, the extant shrew of Sicily was assigned by Corbet (1978) to the Greater white-toothed shrews C. rus- 
sula, whereas the only extant species on Malta, now restricted to the small island of Gozo, was assigned by Schembri and Schembri (1979) to the lesser white-toothed shrew $C$. suaveolens. The extant shrews were thought to have originated either from Italy or Africa and been introduced by human settlers in the Holocene, as summarized in Fig. 1A.

This view changed when chromosome studies of the extant shrew of Sicily revealed a karyotype of $2 n=36$, previously unknown from the Mediterranean region but identical to that of the shrew from Gozo (Vogel et al., 1990). For this taxon, the oldest available name, Crocidura sicula Miller, 1900, was applied, and Hutterer (1990) suggested conspecificity with the fossil $C$. esuae.

The interpretation of an endemic Siculo-Maltese shrew species was subsequently challenged by Sarà (1995). Based on a morphometric study of these shrews and the Canary shrew $C$. canariensis, which all share the same karyotype
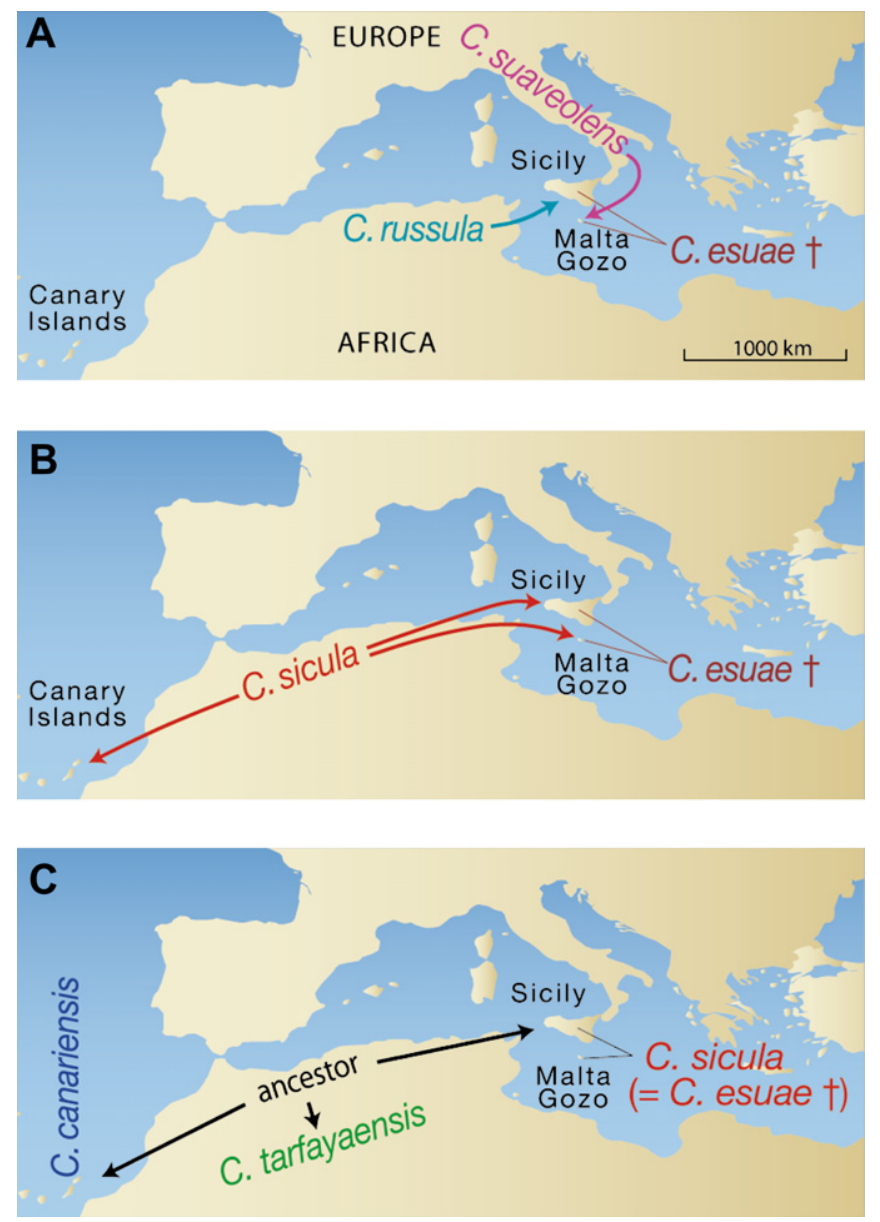

Fig. 1. Hypotheses of the origin of shrews from Sicily, Malta/Gozo, and the Canary Islands. (A) Hypothesis of Kotsakis (1984): the fossil species $C$. esuae was replaced by two introduced species $(C$. russula and $C$. suaveolens). (B) Hypothesis of Sarà (1995): C. sicula migrated to the Canary Islands and Sicily from an unknown population in North Africa, replacing the fossil C. esuae. (C) Hypothesis of Vogel et al. (2006): C. sicula $(=$ C. esuae $)$ on Sicily and C. canariensis on the Canary Islands are endemic species that evolved from a dispersing North African ancestor that may be related to the recent Saharan shrew C. tarfayaensis.
(Hutterer et al., 1987), Sarà (1995) concluded that all should be assigned to the Sicilian shrew $C$. sicula, except for the fossil $C$. esuae. This led to a new hypothesis (Fig. 1B) of a late Pleistocene dispersal to the Canary Islands and Sicily over land bridges from an unknown African $C$. sicula population.

The first molecular investigation to be conducted (Vogel et al., 2003) revealed a genetic divergence of Kimura twoparameter distance $(\mathrm{K} 2 \mathrm{P})$ of $14.3 \%$ between the shrews of Sicily and those of the Canary Islands, clearly higher than the level of intraspecific populations (Bradley and Baker, 2001). This result led us to suggest a third hypothesis concerning the origin of these island shrews; namely, an African ancestor of both species that is either extinct or survives in an extant species (Fig. 1C). Such a potential ancestor was recently found (Vogel et al., 2006) when a cytotaxonomic analysis of the Saharan shrew C. tarfayaensis revealed an identical karyotype of $2 n=36$. The discovery of this shrew opened the way to a new molecular investigation to test not only the hypothesis of a common African ancestor, but also to determine the period of colonization using the molecular clock approach and to develop a plausible scenario of colonization events.

\section{Materials and methods}

\subsection{Sampling, extraction, and DNA amplification}

We analyzed 17 samples of Crocidura from nine different species distributed around the Mediterranean basin and the Canary Islands (Table 1), a more distant crocidurine shrew, Suncus murinus was used as outgroup. Most of the shrews analyzed in this study are from the IZEA collection (University of Lausanne, Switzerland). The two sequences of Crocidura suaveolens were taken from Dubey et al. (2006).

DNA extraction was carried out using a QIAamp DNA Mini Kit (Qiagen). Double-stranded DNA amplifications of cytochrome $b$ gene were performed with the primer pairs L14841/C4, C1/C2, C3/H15915, and L14841/H15915 (Irwin et al., 1991; Dubey et al., 2006). Amplification conditions consisted of 35 thermal cycles of $30 \mathrm{~s}$ denaturation (60 s for the set L14841/H15915) at $94{ }^{\circ} \mathrm{C}, 45 \mathrm{~s}$ annealing $(60 \mathrm{~s}, \mathrm{~L} 14841 / \mathrm{H} 15915)$ at $50^{\circ} \mathrm{C}$, and $60 \mathrm{~s}(120 \mathrm{~s}, \mathrm{~L} 14841 /$ $\mathrm{H} 15915)$ extension at $72{ }^{\circ} \mathrm{C}$. For details on DNA purification and cycle sequencing see Dubey et al. (2007a).

\subsection{Phylogenetic analyses}

Nucleotide sequences of $c y t-b$ gene were edited with Sequence Navigator (Parker, 1997) and aligned by eye. Three methods of phylogenetic analyses were carried out using PAUP* version 4.0b10 PPC (Swofford, 1998). Tests were conducted on the total fragments ( $985 \mathrm{bp}$ ), all codon positions were used, and trees were rooted using sequence of S. murinus. A neighbour-joining (NJ) tree was constructed using Kimura two-parameter genetic distances (Kimura, 1980). This distance was chosen because it allows 
Table 1

Species sequenced and used in the present study (identification number on Fig. 2), collection code, geographic origin of samples, and GenBank accession number

\begin{tabular}{llll}
\hline Species & Coll. code & Locality & GenBank \\
\hline Crocidura canariensis $(1)$ & IZEA 4285 & Fuerteventura, Canary Islands, spain & DQ521042 \\
Crocidura canariensis $(2)$ & LJCC3 & Lanzarote, Canary Islands, Spain & DQ975247 \\
Crocidura ichnusae & IZEA 4011 & Tunisia & DQ975240 \\
Crocidura leucodon & IZEA 6038 & Turkey & DQ975249 \\
Crocidura olivieri & IZEA 3077 & Central African Republic & DQ975250 \\
Crocidura russula & IZEA 5936 & Spain & DQ975238 \\
Crocidura russula & IZEA 2641 & Morocco & DQ975239 \\
Crocidura sicula & IZEA 2943 & Sicily, Italy & DQ521040 \\
Crocidura sicula & IZEA 4000 & Gozo, Malta & DQ975241 \\
Crocidura suaveolens & IZEA 3191 & Spain & AY843491 \\
Crocidura suaveolens & IZEA 7945 & Italy & AY843459 \\
Crocidura tarfayensis $(1)$ & IZEA 7807 & Morocco & DQ975242 \\
Crocidura tarfayensis $(2)$ & IZEA 7808 & Morocco & DQ975243 \\
Crocidura tarfayensis $(3)$ & IZEA 7811 & Morocco & DQ975244 \\
Crocidura tarfayensis $(4)$ & IZEA 7809 & Morocco & DQ975245 \\
Crocidura tarfayensis $(5)$ & ZFMK 2000.039 & Morocco & DQ975246 \\
Crocidura zimmermanni & IZEA 2053 & Crete, Greece & DQ521041 \\
Suncus murinus & IZEA V546 & India & DQ630386 \\
\hline
\end{tabular}

us to compare our results with others studies. Parsimony analyses (MP) were performed using the following options: heuristic search, stepwise-addition of sequences, 10 replicates of random addition of taxa, and TBR branch swapping (Swofford, 1998); all codon positions were equally weighted. For ML analyses, likelihood ratio tests, implemented with the computer program Modeltest 3.06, were first used to choose the mutation model that best fit the data (36). The $\mathrm{GTR}+\mathrm{I}+\mathrm{G}$ model was selected with base frequencies $(\mathrm{A}=0.3024, \mathrm{C}=0.2978, \mathrm{G}=0.1195$, $\mathrm{T}=0.2804$ ) estimated from the data, an unequal distribution of rates at variable sites $(\alpha=1.9972)$, and six different substitution types (rate $[\mathrm{A}-\mathrm{C}]=1.8238$, rate $[\mathrm{A}-\mathrm{G}]=$ 12.4629 , rate $[\mathrm{C}-\mathrm{T}]=28.7198$, rate $[\mathrm{A}-\mathrm{T}]=2.0043$, rate $[\mathrm{C}-\mathrm{G}]=0.4372$, rate $[\mathrm{G}-\mathrm{T}]=1.0000)$. Maximum likelihood analyses were then performed, assuming this model, using the heuristic search option with a stepwise addition of sequences. NJ, MP, and ML results were compared for congruence of tree topologies. Bootstrap support values were obtained with 1000 pseudoreplicates for MP, NJ, and ML analyses, and 10 random replicates of stepwise-addition sequences.

\subsection{Molecular clock analyses}

The molecular clock hypothesis was tested following Posada and Crandall (1998) calculating the log likelihood score with molecular clock enforced and comparing it with the log likelihood previously obtained without enforcing the molecular clock. In addition, to identify whether there was heterogeneity in the rates of $c y t$ - $b$ substitutions among species, relative-rate tests were conducted between each of them, using RRTREE, version 1.0 (Robinson et al., 1998), which improves the test of $\mathrm{Wu}$ and $\mathrm{Li}$ (1985). Relative-rate tests were performed on the proportions of synonymous
$\left(K_{\mathrm{s}}\right)$, non-synonymous $\left(K_{\mathrm{a}}\right)$ substitutions. The Bonferroni correction (Rice, 1989) was applied to deal with statistical artifacts created by multiple comparisons.

Estimation of the divergence time from the molecular data was performed according to a calibration developed previously for the Soricidae by Fumagalli et al. (1999), and that allowed fully coherent results in a biogeographic point of view (see, e.g., Vogel et al., 2003; Brändli et al., 2006; Cosson et al., 2005; Dubey et al., 2006, 2007a,b). This calibration is based on an estimate of 20 million years for the split between Crocidurinae and Soricinae shrews, and it was developed considering the cytochrome $b$ sequence divergences based on third position transversions, with a rate of $1.36 \% / \mathrm{Myr}$ (95\% confidence interval: $1.08-1.64 \%$ / Myr).

\section{Results and discussion}

For this investigation, based on the sequence of $998 \mathrm{bp}$ of the cytochrome $b$ gene, we analyzed the Saharan shrew C. tarfayaensis from Morocco, the Sicilian shrew C. sicula from Sicily and Gozo, and the Canarian shrew C. canariensis from Fuerteventura and Lanzarote. Several other African and three continental European shrew species were included to test possible relationships (see Section 2). The results of this analysis are shown in Fig. 2. The maximum likelihood tree clearly reveals that the $2 n=36$ chromosome group is an independent clade, separate from all other European species.

Relative-rate tests revealed that there were no significant divergences in evolutionary rate between species; and in addition the likelihood ratio test led to acceptance of the molecular clock hypothesis $\left(\chi^{2}=17.62, \mathrm{ddl}=15, p=0.28\right)$.

The first split separated the Sicilian shrew $C$. sicula from the North African ancestor when the species reached the 


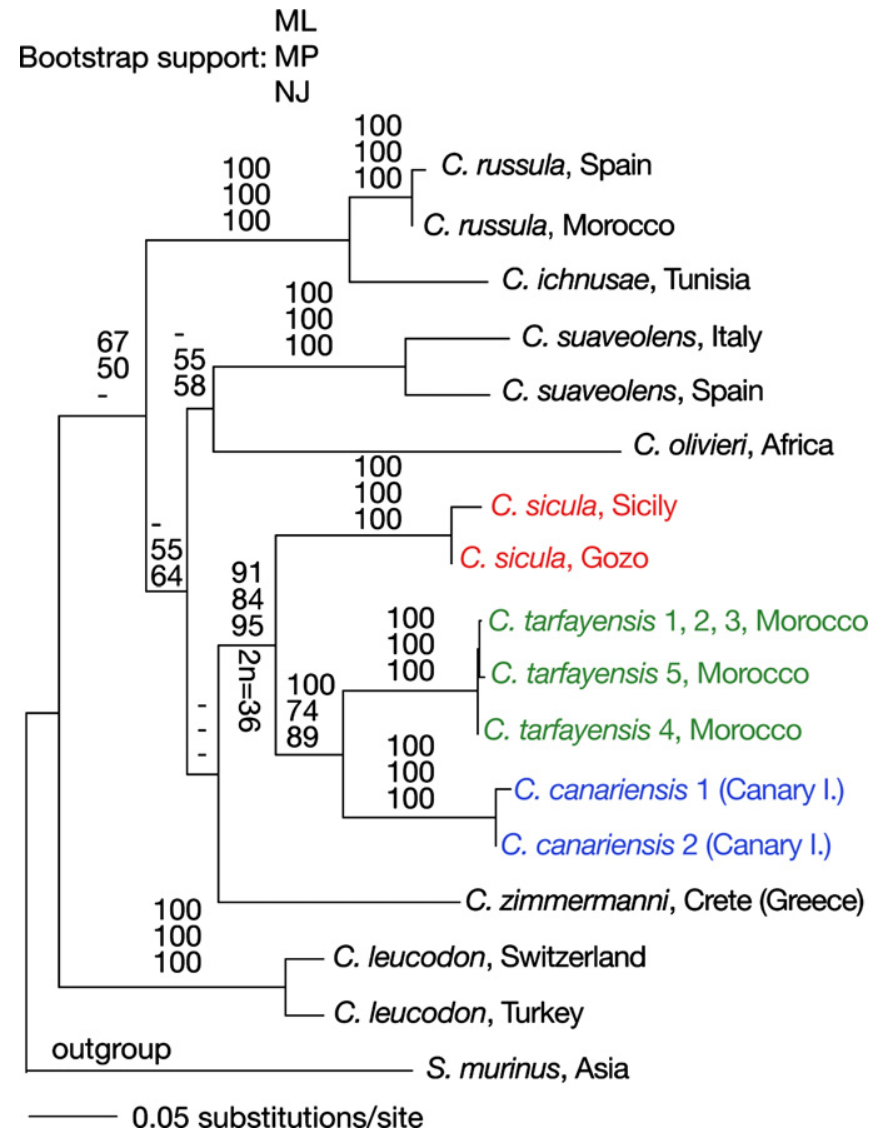

Fig. 2. Maximum likelihood tree of all European and some African Crocidura species. The Asian house shrew Suncus murinus is used as outgroup. The $2 n=36$ chromosome species cluster together. The Sicilian shrew $C$. sicula split off first at a time estimate that is concordant with the Messinian sea regression. The Canary shrew $C$. canariensis split off during the Pliocene. Bootstrap support from maximum likelihood (ML), maximum parsimony (MP) and neighbour-joining analyses (NJ).

Siculo-Maltese archipelago. The divergence between this branch and the remaining African clade (C. tarfayaensis and $C$. canariensis), as estimated from the $\mathrm{K} 2 \mathrm{P}$ value, is equivalent to $14.5 \%$. The molecular clock approach dates this split at approximately $4.65 \mathrm{Myr}$ B.P. (95\% CI: 3.12 6.98). This date is close to the Miocene-Pliocene boundary, and the upper estimate clearly pre-dates this period, characterized by the Messinian salinity crisis that led to the partial evaporation of the Mediterranean Sea and the formation of the most recent land connection between North Africa and continental Europe. At that time, the Siculo-Maltese archipelago was a mountain chain emerging from the partially dry or salt marsh basin characterized by a large "Lago Mare" (Krijgsman et al., 1999). The connection can be compared to a filter bridge (Simpson, 1940) that enables the passage of only a small number of mammals in each direction, from both continental Europe or from Africa.

The divergence between the Sicily and Gozo populations is $1.45 \%$, equivalent to a split at approximately $670,000 \mathrm{yr}$ B.P. (95\% CI: $560,000-840,000)$. This interval lies within a major cold period (Hunt and Schembri, 1999) during which time a lowering of the sea level created a land passage between Sicily and Malta. It seems most likely that this shrew survived on Sicily for 4 million years because of the complex geomorphological structures that resulted from the high altitudinal gradient of the island; part of this population then dispersed to Malta and Gozo. While remains from the Ghar Dalam cave on Malta testify to the presence of shrews at this site since the Middle Pleistocene, they also show that the population became extinct. This extinction may have resulted from stochastic events in ancient time or more recent modifications of the landscape by humans. The surviving shrew population on Gozo, an island of just $14 \mathrm{~km}$ in length, is therefore of great interest from the perspectives of both science and conservation.

A comparison of the Canary and Saharan shrews, $C$. canariensis and C. tarfayensis, reveals a different picture. The divergence is about $12 \%$, and the molecular clock approach reveals a split at $2.68 \mathrm{Myr}$ B.P. (95\% CI: $1.61-$ 4.30), within the Pliocene. As the Canary Islands were never connected to continental Africa (Steiner et al., 1998), jump dispersal via a natural raft, e.g., a rotten tree trunk with holes must be considered as the most likely mode of colonization. Such a transfer, often inferred from fossil data, has recently been demonstrated for arboreal reptiles during hurricanes (Censky et al., 1998). In regard to the Canary Islands, such transfer is plausible for heterothermic reptiles as Gekkonidae, Lacertidae, and Scincidae, but less probable for shrews with a generally high metabolic rate (Vogel, 1976). However, in contrast to the temperate red-toothed shrews (subfamily Soricinae), the white-toothed shrews (subfamily Crocidurinae) have a rather moderate metabolism. Moreover, they are able to reduce the energy expenditure by torpor during low food availability (Nagel, 1977), especially shrews from desert environment (Sparti, 1990), increasing the probability of a successful transfer. Different to reptiles that dispersed to most of the volcanic islands by rafting (Juan et al., 2000), the shrew remained in the complex of eastern islands Fuerteventura, Lanzarote, Lobos, and Montana Clara that were certainly connected during low sea levels, a fact that is in agreement with the lower probability of a rafting success.

Our new data support the last hypothesis (Fig. 1C), that the island shrews represent two different endemic species whose ancestors reached the islands from North Africa without human assistance. Their precursor survived on the continent as its descendent, the Saharan shrew. These processes are in contrast with the colonization of most other Mediterranean islands by continental species that were passively introduced by humans over the past 12,000 yr, e.g., the North African white-toothed shrew $C$. ichnusae to Sardinia, Pantelleria, and Ibiza (Cosson et al., 2005), and a subspecies of the lesser white-toothed shrew C. suaveolens gueldenstaedtii to Crete, Corsica, and Menorca (Dubey et al., 2007a, 2006). A Canary Island population 
of the greater white-toothed shrew C. russula (originally described as $C$. osorio from Gran Canaria) was possibly introduced from Spain by the Spanish conquistadors (Vogel et al., 2003). In conclusion, shrews represent a highly interesting model organism in terms of illustrating different processes of island colonization.

\section{Acknowledgments}

We thank Charlotte Vogel-Gerber for her help in trapping C. tarfayaensis and C. sicula, P.J. Schembri for his assistance in trapping C. sicula on Gozo, Nelly Di Marco for management of the tissue collection, T. Czáka for the map design, and P. Moratal for computer facilities. The Herbette Foundation (Lausanne) provided travel funds.

\section{References}

Bradley, R.D., Baker, R.J., 2001. A test of the genetic species concept: cytochrome-b sequences and mammals. J. Mammal. 82, 960-973.

Brändli, L., Handley, L-J., Vogel, P., Perrin, N., 2006. Evolutionary history of the greater white-toothed shrew (Crocidura russula) inferred from analysis of mtDNA, Y, and $\mathrm{X}$ chromosome markers. Mol. Phylogenet. Evol. 37, 832-844.

Censky, E.J., Hodge, K., Dudley, J., 1998. Over-water dispersal of lizards due to hurricanes. Nature 395, 556.

Corbet, G.B., 1978. The Mammals of the Palaearctic Region: A Taxonomic Review. Cornwell University Press, British Museum (Natural History), p. 314.

Cosson, J.F., Hutterer, R., Libois, R., Sarà, M., Taberlet, P., Vogel, P., 2005. Phylogeographic footprints of the Strait of Gibraltar and Quarternary climatic fluctuations in the western Mediterranean: a case study with the greater white-toothed shrew Crocidura russula (Mammalia: Soricidae). Mol. Ecol. 14, 1151-1152.

Cucchi, T., Orth, A., Auffray, J.C., Renaud, S., Fabre, L., Catalan, J., Hadjisterkotis, E., Bonhomme, F., Vigne, J.D., 2006. A new endemic species of the subgenus Mus (Rodentia, Mammalia) on the Island of Cyprus. Zootaxa 1241, 1-36.

Diamond, J.M., 1969. Avifaunal equilibria and species turnover rates on the Channel islands off California. Proc. Nat. Acad. Sci. USA 64, $57-63$.

Diamond, J.M., 1992. Twilight of the pygmy hippo. Nature 359, 15.

Dubey, S., Cosson, J-F., Magnanou, E., Vohralik, V., Benda, P., Frynta, R., Hutterer, R., Vogel, P., 2007a. Mediterranean populations of the Lesser white-toothed shrew (Crocidura suaveolens group): an unexpected puzzle of Pleistocene survivors and prehistoric introductions. Mol. Ecol. 16, 3438-3452.

Dubey, S., Cosson, J-F., Vohralik, V., Krystufek, B., Diker, E., Vogel, P., 2007b. Molecular evidence of Pleistocene bidirectional faunal exchange between Europe and the Near East: the case of the bicolored shrew (Crocidura leucodon, Soricidae). J. Evol. Biol. 20, 1799-1808.

Dubey, S., Zaitsev, M., Cosson, J.-F., Abdukadier, A., Vogel, P., 2006. Pliocene and Pleistocene diversification and multiple refugia in a Eurasian shrew (Crocidura suaveolens group). Mol. Phylogenet. Evol. $38,635-647$.

Fumagalli, L., Taberlet, P., Stewart, D.T., Gielli, L., Hausser, J., Vogel, P., 1999. Molecular phylogeny and evolution of Sorex shrews (Soricidae: Insectivora) inferred from mitochondrial DNA sequence data. Mol. Phylogenet. Evol. 11, 222-235.

Hunt, C.O., Schembri, P.J., 1999. Quarternary environments and biogeography of the Maltese Islands. In: Mifsud, A., Savona Ventura, C. (Eds.), Facets of Maltese Prehistory. The Prehistoric Society of Malta, Malta, pp. 41-75, vii + pp. 243.
Hutterer, R., 1990. Temporal and geographical variation of shrews of the Sicilian-Maltese archipelago since the Pleistocene. Vie Milieu 40, 213-217.

Hutterer, R., López Jurado, L.F., Vogel, P., 1987. The shrews of the eastern Canary Islands: a new species (Mammalia, Soricidae). J. Nat. Hist. 21, 1347-1357.

Irwin, D.M., Kocher, T.D., Wilson, A.C., 1991. Evolution of the cytochrome $b$ gene of mammals. J. Mol. Evol. 32, 128-144.

Juan, C., Emerson, B.C., Oromí, P., Hewitt, G.M., 2000. Colonization and diversification: towards a phylogeographic synthesis for the Canary Islands. Trends Ecol. Evol. 15, 104-109.

Kimura, M., 1980. A simple method for estimating evolutionary rate of base substitution trough comparative studies of nucleotide sequences. J. Mol. Evol. 16, 111-120.

Kotsakis, T., 1984. Crocidura esui n. sp. (Soricidae, Insectivora) du Pléistocène de Spinagallo (Sicilie orientale, Italie). Geol. Rom. 23, 51-64.

Krijgsman, W., Hilgen, F.J., Raffi, I., Sierro, F.J., Wilson, D.S., 1999. Chronology, causes and progression of the Messinian salinity crisis. Nature 400, 652-655.

McArthur, R.H., Wilson, E.O., 1967. The Theory of Island Biogeography. Princeton Univ. Press, Princeton, NJ.

Nagel, A., 1977. Torpor in the European white-toothed shrews. Experientia 33, 1455-1456.

Parker, S.R., 1997. Sequence Navigator. Multiple sequence alignment software. Methods Mol. Biol. 70, 145-154.

Posada, D., Crandall, K.A., 1998. MODELTEST: testing the model of DNA substitution. Bioinformatics 14, 817-818.

Rice, W.R., 1989. Analyzing tables of statistical tests. Evolution 43, 223-225

Robinson, M., Gouy, M., Gautier, C., Mouchiroud, D., 1998. Sensitivity of the relative-rate test to taxonomic sampling. Mol. Biol. Evol. 15, 1091-1098.

Sarà, M., 1995. The Sicilian (Crocidura sicula) and the Canary $(C$. canariensis) shrew (Mammalia, Soricidae): peripheral isolate formation and geographic variation. Boll. Zool. 62, 173-182.

Schembri, P.J., Schembri, S.P., 1979. On the occurrence of Crocidura suaveolens Pallas, (Mammalia, Insectivora) in the Maltese Islands with notes on other Maltese shrews. Cent. Medit. Nat. 1, 18-21.

Simpson, G.G., 1940. Mammals and land bridges. J. Wash. Acad. Sci. 30, 137-163.

Sondaar, P.Y., 1977. In: Hecht, M.K., Goodey, P.C., Hecht, B.M. (Eds.), Major Patterns in Vertebrates Evolution. Plenum, New York, pp. 671-707.

Sparti, A., 1990. Comparative temperaure regulation of African and European shrews. Comp. Biochem. Physiol. 97A, 391-397.

Steiner, C., Hobson, A., Favre, P., Stampfli, G.M., Hernandez, J., 1998. Mesozoic sequence of Fuerteventura (Canary Islands): witness of early Jurassic sea-floor spreading in the central Atlantic. GSA Bull. 10, 1304-1317.

Swofford, D.L., 1998. PAUP*. Phylogenetic Analysis Using Parsimony (* and other Methods). Version 4.0b1. Sinauer Associates, Sunderland, MA.

Vogel, P., 1976. Energy consumption of European and African shrews. Acta Theriol. 21, 195-206.

Vogel, P., 1986. Der Karyotyp der Kretaspitzmaus, Crocidura zimmermanni Wettstein, 1953 (Mammalia, Insectivora). Bonn. Zool. Beitr. 37, 35-38.

Vogel, P., Maddalena, T., Catzeflis, F., 1986. A contribution to taxonomy and ecology of shrews from Crete and Turkey (Crocidura zimmermanni and C. suaveolens). Acta Theriol. 39, 537-545.

Vogel, P., Cosson, J.-F., López Jurado, L.F., 2003. Taxonomic status and origin of the shrews (Soricidae) from the Canary Islands inferred from a mtDNA comparison with the European Crocidura species. Mol. Phylogenet. Evol. 27, 271-282.

Vogel, P., Mehmeti, A.-M., Dubey, S., Vogel-Gerber, C., Koyasu, K., Ribi, M., 2006. Habitat. Morphology and karyotype of the Saharan 
shrew Crocidura tarfayaensis (Mammalia: Soricidae). Acta Theriol. 51, 353-361.

Vogel, P., Schembri, P.J., Borg, M., Sultana, J., 1990. The shrew (Crocidura sp.) of Gozo, a probable survivor of the Pleistocene fauna of Mediterranean Islands. Z. Säugetierkunde 55, 357-359.
Williamson, M., 1981. Island Populations. Oxford Univ. Press, Oxford, p. 286.

Wu, C.I., Li, W.H., 1985. Evidence for higher rates of nucleotide substitutions in rodents than in man. Proc. Natl. Acad. Sci. USA 82, 1741-1745. 